\title{
Author Correction: Mitochondrial haplotypes affect metabolic phenotypes in the Drosophila Genetic Reference Panel
}

Roel P. J. Bevers (1D, Maria Litovchenko, Adamandia Kapopoulou, Virginie S. Braman, Matthew R. Robinson, Johan Auwerx (D), Brian Hollis and Bart Deplancke (iD

Correction to: Nature Metabolism https://doi.org/10.1038/s42255-019-0147-3, published online 9 December 2019.

In the version of this article initially published, in the $x$-axis labels in Fig. 6d,e, MH1 should have read MH5 and vice versa. The error has been corrected in the HTML and PDF versions of the article.

Published online: 6 April 2020

https://doi.org/10.1038/s42255-020-0202-0

๑ The Author(s), under exclusive licence to Springer Nature Limited 2020 